\title{
HOW SEX ED FAILS PEOPLE WITH PERIODS
}

\section{DARA E. PURVIS*}

Long before I taught law students the intricacies of statutes, I taught junior high school students sex education. It was a part-time job while I was in college in Los Angeles, through a program with Planned Parenthood that provided a two-week curriculum in public junior high schools. Today I joke that it gave me my unflappable nature in the classroom - if you can tell preteens about syphilis, nothing that happens in a law school classroom will break your concentration - but it also gave me an indelible memory of how far sex ed in America has to go. During our training, one of my fellow teachers referred in passing to how annoying it was to change her tampon every time she had to urinate. She was a bright college student and engaged with reproductive work enough that she successfully applied to work at Planned Parenthood. Yet, she didn't know that the vagina and urethra were different anatomical structures.

That experience was a dramatic example, but it is merely the tip of the iceberg when it comes to ignorance about periods. Students are still often separated by gender when the bodily developments of puberty are discussed ${ }^{1}$ - that is, if they receive any sex ed beyond instructions to remain abstinent until marriage. ${ }^{2}$ Even if they are in the room, no statutory guidance as to the required topics moves beyond the abstract notion of a period to talk about practicalities: what are pads, tampons, and cups; how many are needed for an average period; and so on. ${ }^{3}$ This lack of education, coupled with the taboo of menstruation, means that, on the whole, most men lack any real sense of the day-to-day impact of menstruating.

\footnotetext{
* Professor, Penn State Law; J.D., Yale Law School; M.Phil., University of Cambridge; B.A., University of Southern California.

${ }^{1}$ See Margaret E. Johnson, Emily Gold Waldman \& Bridget J. Crawford, Title IX \& Menstruation, 43 HARV. J. L. \& GENDER 225, 279 n.243 (2020).

${ }^{2}$ See Hazel Glenn Beh \& Milton Diamond, The Failure of Abstinence-Only Education: Minors Have A Right to Honest Talk About Sex, 15 Colum. J. GeNDER \& L. 12, 25-33 (2006) (outlining impact of federal funding policies on abstinent-only sex education); Sarah Smith Kuehnel, Abstinence-Only Education Fails African American Youth, 86 WASH. U.L. REV. 1241, 1253-54 (2009) (describing growth in abstinence-only education).
}

${ }^{3}$ See Johnson et al., supra note Error! Bookmark not defined., at 258. 
Sometimes this is funny-perhaps the best-known example of this is NASA asking astronaut Sally Ride if one hundred tampons would be sufficient for a one-week voyage - but there are more serious reasons why men not knowing the practicalities of menstruation is harmful.

Most directly, some of the children in the classroom for "boys" who receive almost no information about menstruation are intersex and will experience menstruation without knowing what it is. The term intersex is used to mean any "reproductive or sexual anatomy that doesn't seem to fit the typical definitions of female or male." ${ }^{4}$ Sometimes the variation in an intersex person's anatomy is immediately apparent at birth, but differences may only become apparent at puberty or later in life, if at all. ${ }^{5}$ This was the experience of Maya Posch, who was assigned the male sex at birth and only discovered in her mid-twenties that she was intersex. ${ }^{6}$ As a child, she experienced "horrible cramping" and thought she was dying, in what she later realized was the onset of her menstruation. ${ }^{7}$

Additionally, almost all the children in the "boys" classroom will grow up to be employers and coworkers of women, and their lack of knowledge will harm women in the workforce as they fail to provide adequate supplies, breaks, or sick time. Margaret Johnson has chronicled examples of employment discrimination lawsuits, such as one employee who was fired for accidentally getting menstrual blood on a chair and carpet at work. ${ }^{8}$ In that case, the employee was experiencing heavier than normal and unpredictable periods, as she was premenopausal. ${ }^{9}$ Her employer viewed this as a failure of "personal hygiene" rather than a medical condition, ${ }^{10}$ a rush to judgment that might have been mitigated by more knowledge about how menstruation works.

\footnotetext{
${ }^{4}$ What is Intersex?, INTERSEX SOC'Y OF N. AM., https://isna.org/faq/what_is_intersex/[https://perma.cc/73L5LZL5].

${ }^{5}$ See Anne Tamar-Mattis, Exceptions to the Rule: Curing the Law's Failure to Protect Intersex Infants, 21 BERKELEY J. GENDER L. \& JUST. 59, 63-64 (2006).

${ }^{6}$ See Maya Posch, What Puberty is Like as an Intersex Person, Clue (Feb. 11, 2019) https://helloclue.com/articles/culture/what-puberty-is-like-as-an-intersex-person [https://perma.cc/9AYDD9TG].

${ }^{7} I d$.

${ }^{8}$ See Margaret E. Johnson, Menstrual Justice, 53 U.C. DAvis L. Rev. 1, 30-31 (2019).

${ }^{9}$ See id. at 31.

${ }^{10} I d$.
} 
Another failure of this lack of information affects entrepreneurs, as investors don't understand the need for better period products and withhold funds and other backing from female entrepreneurs. Jordana Kier and Alex Friedman, the founders of a company that makes products supporting menstruation, wrote about their experience seeking investors in Harper's Bazaar. They "convinced a man to invest in us by dunking a tampon in a cup of water over a business lunch," realizing he had no idea how tampons worked. ${ }^{11}$ They wrote, "In the three years since we started LOLA and found ourselves dumbfounded in that first pitch meeting, encounters like these have become routine . . . 'So, you just use one tampon a month? Then a box of 18 would last you a year and a half?", 12

Failing to educate all children about menstruation affects people who menstruate throughout adulthood. Treating menstruation as a niche topic that is not appropriate for general education and conversation directly harms people who menstruate. If sex ed pivots to teaching all students what having a period is like, those students will grow up to be adults who view menstruation as normal. Practicality and empathy in the classroom are never wasted - and, in this case, have the potential to end the unease and unfairness that extend far beyond the biological sphere.

\footnotetext{
${ }^{11}$ See Olivia Fleming, Jordana Kier, \& Alex Friedman, How to Teach Men About Period Paraphernalia, HARPER's BAZAAR (July 20, 2017), https://www.harpersbazaar.com/culture/a10336531/teaching-men-abouttampons/ [https://perma.cc/S474-ZBDL].

${ }^{12} I d$.
} 